\title{
The Impact of English on Armenian
}

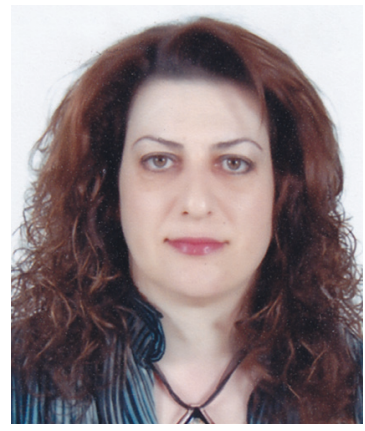

Anahit Galstyan

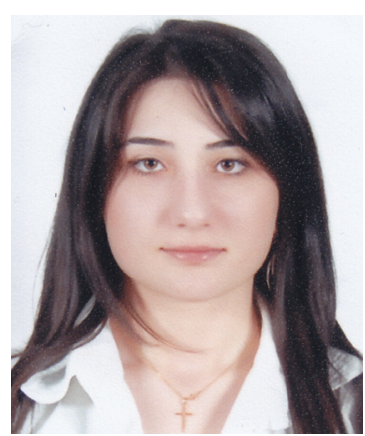

Julietta Sargsyan

耳 nglish is today a truly global language. This has

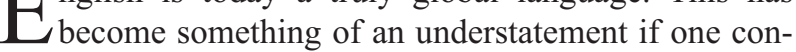
siders the dramatic expansion in the roles of English as a language of international communication in trade, diplomacy, sport, science, technology and countless other fields in a growing number of regions and cultural contexts. More recently, revolutions in transport, technology, commerce and communications including satellite broadcasting and the Internet, have all further reinforced the global pre-eminence of English. The global spread of English, its causes and consequences have long been a focus of critical discussion. However, in recent years one of the main concerns has become the relation between the international or lingua franca English (LFE) and the national languages. Some are under heavy pressure of LFE, others are slightly influenced by it.

The aim of the present research is to study the impact of English on the Armenian language and culture. The issues to be discussed are as follows:

1 Is English a foreign language used as lingua franca in relation to other foreign languages traditionally studied and used in Armenia?

2 What is the impact of English on the Armenian language and culture?

3 What attitudes have evolved from this impact?

A sociolinguistic investigation has been carried out to answer these questions. Information has been drawn from two sources: seventy respondents of different age, profession and sex have been questioned by us, whereas the second source of information is the collection of data from articles, hoardings, specialized dictionaries.

Touching upon the first problem, we can surely say that English is not perceived as LF in Armenia. For one thing, Russian continues influencing Armenian. For another thing, Armenians are not competent enough in English.

As we know, in the former Soviet Union a large number of regional languages, among them Armenian, were under heavy pressure of Russian. Now, following the fall of the Soviet Union, the languages spoken in the different ex-republics can be expected to be given a fresh lease of life. Indeed, after the proclamation of Independence from the USSR in 1991 English replaced Russian in many domains (it has become the language of business, diplomacy, tourism, science, computer etc.). However, Russian continues influencing Armenian in many aspects (due to the political, economic, social, etc. relations). 
On the other hand, many Armenians (especially the middle-aged and the elderly) have a low level of competence in English and they have to read Russian translations of English books, journals, articles (mainly on marketing, sociology, modern technology and so on). Besides, most Armenians go on using Russian in everyday speech.

Our survey has revealed that English is perceived as the main foreign language studied and used in Armenia and by Armenians.

English has become the foreign language that much of the world wants to learn. The more English-speaking the world becomes, the more desirable the language becomes to all societies. The learner's major reason for studying English is to communicate with other non-native as well as native speakers. It is noteworthy that nearly 90 percent of offices require a good knowledge of English, instead of German, Russian, French and many other foreign languages traditionally studied and used in Armenia and by Armenians. It is noteworthy that learning English has become a must in Armenia (among fifty respondents thirty-seven claim this).

As cultural carrier, English is also perceived as the vehicle for the import of Anglo-Saxon culture, mostly American, which again triggers mixed feelings towards English as a globalized language. Many people are concerned that the worldwide spread of English is accompanied by a form of "cultural imperialism", whereby Anglophone cultures seem to impose themselves on all over cultures and Armenian is not an exception.

English has become the language of international popular culture for today's youth. The language of "Eurovision" song contest is English which contributes to the creation of new songs in English. Let's remember Andre's song "Without Your Love", Sirusho's "Qele-Qele", or the song that was sung by Anush and Inga Arshakyans at the contest. The cultural influence brought to the borrowing of such words as

- Engl. show-business - Arm. [Joubiznes]

- Engl. clipmaker - Arm. [klipmejker]

- Engl. casting - Arm. [kasting]

- Engl. band - Arm. [bend]

- Engl. superstar - Arm. [superstar]

- Engl. producer - Arm. [prodjuser]

- Engl. image maker - Arm. [imij mejker], etc.

The influence of English can even be seen in the names of Armenian performances, such as "Cuun LOVE STORY", where the word love can be interpreted as shat lav-very good story and love story.

Even the names of companies, shops and cafes bear the influence of English. Such names as Virginia, Aqua Mobile, No Problem, Grand Candy, Lunch Time, In Style, Best, Mr. Toaster, Golden Palace Hotel, Citadel Business Centre, Bar OK, names of taxi companies: Busy, Group, Bus, Globe, Gold Way, Wolf and many others have replaced Armenian names: Aramazd, Marash, Astghik, Salmast, Van, Mush, Ararat, Urartu, Aragats, Kilikia, etc.

Advertising hoardings are also flooded with English words. This billboard, for example, can be found at any metro-station: 


\section{FAST NET}

Dial-up/DSL/Wireless Internet Communication Calling Cards

UhяuqqujhG quuh pupuntp

Prepaid Internet Cards

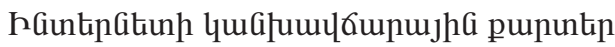

The word card used in this advertisement penetrated into Armenian in the 1990s in combination with such words as credit (credit card), smart (smart card), elastic (elastic card), calling (calling card), internet (internet card), etc. It has undergone phonetic and grammatical assimilation: (pupun $+\mathrm{k}$ p (plural suffix)). This anglicism can also be found in many European languages such as: German - karte; Norwegian - kort (in the1980s); Icelandic - kort; Spanish - non-English term tarjeta (-de credito) is more frequent or acceptable; the Romanian pronunciation is near or identical to that of English etymon; Russian - kart (the spelling differs from that of English etymon). In the 1990s the Russian term became frequently used or accepted rather than its first attestation in dictionaries (non-English term is more frequent or acceptable, rendered into kartochka).

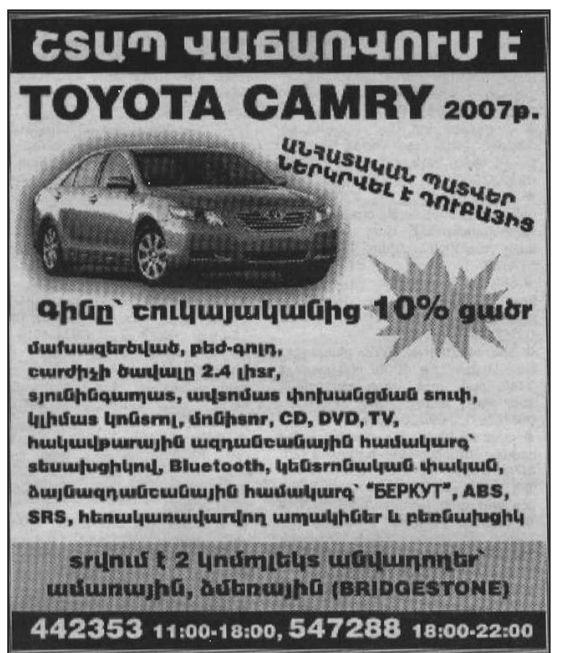

Newspaper advertisements are also full of English words. The following example is taken from the Armenian newspaper "Gind".

As we see beige-gold, bluetooth, CD, DVD, $T V, A B S$, climate control, $S R S$ as well as the hybrid: ıлnıahaquшщu / (Engl. tuning $+u$ + чщши( (џшд) (lit. covered with tuning)) are used in this advertisement.

It is noteworthy, that the number of anglicisms used in Armenian increases day by day. Our journalists, political figures, scientists, businessmen, students prefer the use of English terms to Armenian ones in their reports, interviews, articles. We think that people sometimes use the English words, because the latter are either more prestigious than the Armenian ones, or the speakers have difficulties in finding the Armenian equivalents of the English words. However, most Armenians (forty-one respondents) are not against the usage of English words in Armenian speech. They themselves often use such words as OK, stop, party, please, thank you, love you, you're welcome, let's go, because, so, give up, darling, etc. Seven respondents have negative attitude towards the usage of the English words, they even struggle against it. However, they confess that sometimes they also use English words in Armenian speech unintentionally. 
To sum up, we can say, that attitudes towards English as the dominant foreign language in Armenia fluctuate between positive and negative. However, some Armenians think that the spread of global English may cause the corruption of not only our language but also our culture. Consequently, the threat of ligua franca English makes language planning desirable and indeed necessary. We are certain that language planning must be part of language policy and government policy in general, otherwise our ancient mothertongue will change into Armglish (cf. Spanglish) in several years.

\section{References:}

1. Ans, van Kemenade and Bettelou, Los (Eds) (2006) The Handbook of the History of English. Blackwell Publishing.

2. Crystal, D. (1995) The Cambridge Encyclopedia of the English Language. Cambridge: Cambridge University Press.

3. Crystal, D. (1997) English as a Global Language. Cambridge: Cambridge University Press.

4. Görlach, M. (Ed) (2005) A Dictionary of European Anglicisms. Oxford: Oxford University Press.

5. Mejtikhanyan, P. (1996) Nor bareri batsatrakan bararan. Yerevan: Pyunik.

6. Romaine, S. (2006) Global English: From Island Tongue to World Language. // The Handbook of the History of English. Blackwell Publishing.

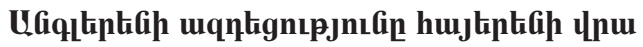

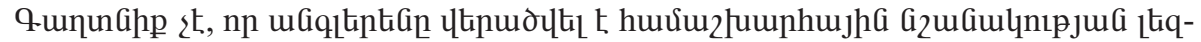

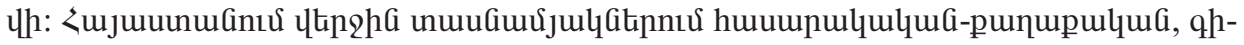

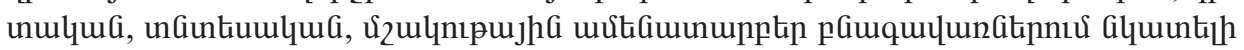

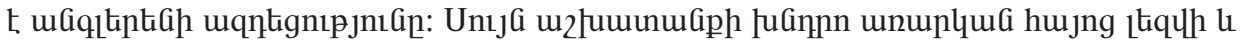

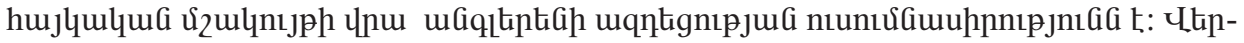

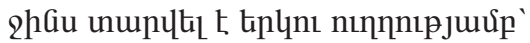

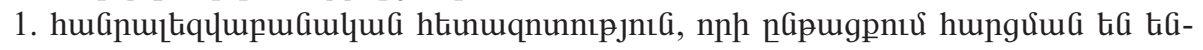

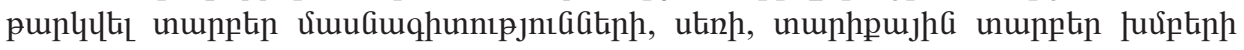

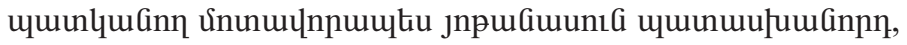

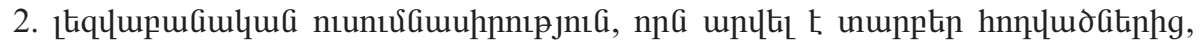

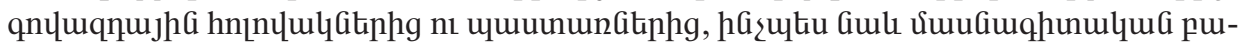

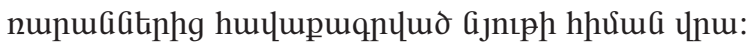

